\title{
Preliminary Results of a StUdy ASSESSing EngINEERING STUDENTS' FORMATION OF IDENTITY AS RHETORICIAN
}

\author{
Debora Rolfes, Corey Owen, and Julie Hunchak \\ Graham School of Professional Development, University of Saskatchewan \\ debora.rolfes@usask.ca,corey.owen@usask.ca,julie.hunchak@usask.ca
}

\begin{abstract}
The difficulty of teaching communication skills to engineering students in a way that facilitates the transfer of knowledge to workplace situations is widely acknowledged. At the College of Engineering at the University of Saskatchewan we have tried to address this difficulty by developing a programme that attempts to add the identity of effective communicator to the students' identity as engineer. The purpose of this study is to begin to assess whether students are forming this identity. Using Burke's concept of terministic screens and the analytical tools of cluster criticism, we analyze the transcripts of interviews of students returning from internship experiences to assess whether students' language choices reflect a rhetorical orientation to the world and thus the development of an identity of rhetorician.
\end{abstract}

Keywords: rhetoric, identity formation, community of practice cluster criticism, terministic screens, rhetorical orientation

\section{INTRODUCTION}

At the College of Engineering at the University of Saskatchewan, the challenge of teaching communication skills to engineering students in a way that facilitates transfer of knowledge from the classroom to the workplace has been met by developing a required communication course and a series of upper level communication electives grounded in rhetorical theory. Our communication programme attempts to teach the skills necessary for effective professional communication by introducing the practical, genre-based technical communication skills while, at the same time, developing students' rhetorical judgment. Drawing upon Wenger's theory of social learning [20], the faculty of the Ron and Jane Graham School of Professional Development attempt to create in the communication classroom, as well as in the broader college context, a community of practice in which students are mentored by instructors, senior students, and their peers in the pursuit of effective rhetorical persuasion skills. In this way, the programme is designed to broaden the professional identity of engineering students to include effective communicator as an integral element and so facilitate transfer of communication skills.

In this paper, after briefly describing how our programme attempts to confer an identity of effective communicator upon our students, we report preliminary results of our study designed to assess our programme's effectiveness. In order to assess the degree of learning transfer our students experience, we have followed Doug Brent's recommendation to seek evidence of transfer through "rigorous interviews" [2]. Our study involves analyzing individual, in-depth interviews with students about their experiences while on internship to assess whether the language used by the student reflects a rhetorical orientation to communication challenges, and thus evidence of identity formation as effective communicator. This information is potentially useful to assess the efficacy of our programme. The rationale and methodology of the study is outlined in detail in Rolfes and Owen, "Some Epistemological Groundwork for a Qualitative Analysis of a Communication Community of Practice" [18].

\section{LITERATURE REVIEW AND THEORETICAL APPROACH}

Researchers can use a variety of qualitative approaches to help them measure the efficacy of an academic programme, most of which involve the analysis of interview transcripts. Of the five approaches to qualitative research identified by Creswell-narrative, phenomenology, grounded theory, ethnography, and case study - we chose narrative because it encourages the close reading of a given narrative and invites the application of linguistic and literary tools of analysis [6]. As we argue in a previous paper,

[n]arrative research, and rhetorical analysis, are useful tools for investigating identity because such approaches are less interested in the facticity of the information provided by participants, and more interested in the qualities of the participant's identity that are manifested through her language and patterns of thought. [18] 
In our analysis of the narratives, we opted to use rhetorical criticism, an approach to analyzing discourse that is employed by both literary scholars and sociologists. According to Sonja Foss, rhetorical criticism is "a process of thinking about symbols, discovering how they work, and trying to figure out why they affect us" [8]. Using this theoretical approach, we analyzed transcripts of interviews with students about internship to assess how they symbolically represent their experiences and possibly what their discourse reveals about their identity.

Identity, as defined by Paul Gee, is a social construct that describes "[d]ifferent ways of being in the world at different times and places for different purposes." For Gee, identity is not identical to one's core sense of self but rather "how we recognize and act out different social roles or different social positions in society" [9]. As a social construct, identity is inculcated and regulated through various verbal and nonverbal rhetorical practices. As Kenneth Kong writes, "Language is not just a means of negotiating personal relationships but it is also crucial to acquiring the values and attributes of the profession and, finally, to socializing participants into desired identities in a profession" [11]. In our study, we attempted to determine whether some measure of the identity of rhetorician is conferred through the rhetorical theory we teach in our professional communication programme. According to the rhetorical theorist Kenneth Burke, "identity is not individual," since people naturally identify themselves "with all sorts of manifestations beyond [themselves]" [3]. Such a process of identification is essential to any organization or collective enterprise, and "[o]ne's participation in a collective, social role cannot be obtained in any other way" [3]. For Etienne Wenger, identity is conferred through practice, and such practice enables one to join a larger community of practitioners, a community that further develops the identity of the practitioner:

There is a profound connection between identity and practice. Developing a practice requires the formation of a community whose members can engage with one another and thus acknowledge each other as participants. As a consequence, practice entails the negotiation of ways of being a person in that context. [20]

In Burke's terminology, through identification one becomes consubstantial with something else, while at the same time one "remains unique, an individual locus of motives" [4]. One can be consubstantial with a variety of entities, while still remaining open to the possibility of further identification; thus, as Wenger observes, membership in a particular community of practice does not necessarily preclude membership in any other community: multimembership is typical, and the complexity of an individual's identity is comprised, to some extent, by the various communities to which she belongs [20].

\section{OUR PROGRAMME}

As Burke argues, the study of rhetoric is the study of identification since rhetorical practices both reflect and promote identification. Identification, and rhetoric, is needed, paradoxically, because of division, the common human experience of separation, or boundaries. Thus, as Burke states, "Identification is compensatory to division" [4]. As Sullivan and Kedrowicz note, and as we argue elsewhere, engineering students generally perceive communication skills as external to their identity, because their identity of practice excludes effective communication skills [19] [15]. As teachers of rhetoric, our job is to attempt to confer an identity of practice, to create a community that enables our students to perceive themselves as both future engineers and effective communicators [16].

Our programme teaches rhetorical criticism, a theoretical approach that involves the analysis of discourse, and thus one that we found useful for analyzing the transcripts of the interviews used in our study. As Sonja Foss writes, "a rhetorical act or artifact ... may provide a vocabulary of thoughts, actions, or attitudes for codifying and thus interpreting a situation"; thus, "Rhetoric ... provides an orientation in some way to a situation and provides assistance in adjusting to it" [8]. "Orientation" is a key term in Burke's theory; as David Blakesley writes,

[a]n orientation is a general view of reality shaped by symbolic interaction with the objects of experience. Orientations may change, but at any given moment they are governed by such things as memory, ideology, training, piety, and social norms. [1]

In using rhetorical theory to teach effective rhetorical practice, our programme promotes an orientation that emphasizes the relational element of communication, as opposed to an approach that emphasizes the teaching of genres, such as letters, memos, resumes, and formal reports. While we do indeed discuss such genres in detail, our discussions are first contextualized within the nine axioms of communication that Jennifer MacLennan identifies, several of which consider different aspects of the element of relation: "Communication is not simply an exchange of ideas or information, but an interaction between people," "All communication involves an element of relation as well as content," "All communication takes place within a context of "persons, objects, events, and relations,", "Communication is a principal way of establishing ourselves and maintaining credibility," "All communication involves an element of interpersonal risk," and "effective professional communication is audiencecentred, not self-centred" [12]. Furthermore, we discuss George Dillon's concept of footing, the codes of engagement rhetors adopt with respect to their audience [7], as well as Erving Goffman's concept of face [10]. 


\section{METHOD}

For rhetorical critics, specific discourses, or artifacts, consist of a particular vocabulary that reveals a worldview, a terministic screen [5]. According to Burke, "even if any given terminology is a reflection of reality, by its very nature as a terminology it must be a selection of reality; and to this extent it must function also as a deflection of reality" [5]. Thus, the very terms a rhetor uses point to an underlying understanding of the world, one that is selected from many possible orientations. In our research, we applied this theory to the transcripts of the interviews with the students returning from an internship: we analyzed the terminology the participants used to determine whether they had internalized a rhetorical orientation, as we teach it in our rhetorical communication programme, that is, an orientation that suggests the thoughtful, reflective, and appropriate use of rhetorical terminology we use in all of our courses.

One of the tools Burke developed to help detect the worldview inherent in a terministic screen is cluster analysis, through which "we interpret the work of a writer [or speaker] through indexing, which involves systematically tracking down the context where important or pivotal terms appear"; the aim of this exercise is to "map the interrelationships among the terms in a given work, the premise being that these formal relationships express a logic rooted in the writer's psychology (conscious or unconscious)" [1]. Following Burke's approach, to analyze the transcripts we coded them in NVivo and identified key terms. Our research group, which comprised two rhetoricians and a practising engineer, then analyzed, both individually and in group discussion, the context in which these key terms appeared, in order to determine the relationship between the terms, and to determine whether the underlying worldview of the participant reflected a rhetorical orientation.

\section{LIMITATIONS}

Our particular experimental design potentially compromises our results in three ways. First, as Rebecca Nowacek observes, students may, consciously or unconsciously, respond to the implied generic expectations of the situation [14]. As Donald Polkinghorne puts it, transcripts of interviews are "creations of an interaction between interviewers and participants" [17]; thus, our participants may have formulated responses simply to satisfy the perceived constraints of the situation. Second, our bias as instructors in the programme may have led us to misinterpret the data. Our use of rhetorical analysis helps avoid any damage caused by the first potential weakness: the search for an orientation through cluster criticism involves close analysis of transcript and, ideally, helps us recognize naïve and/or gratuitous uses of rhetorical terminology. The second risk to the accuracy of our conclusions is characteristic of all qualitative research. To mitigate the effects of this threat, we chose an interviewer who was an engineer, not an instructor of rhetorical communication, and we collaborated with another engineer in the analysis of our results. Ultimately, as is the case for all qualitative research, our interpretation of the evidence is constrained by the evidence provided in the manuscripts and, as Polkinghorne would suggest, relies on principles of argumentation that justify our understanding of the evidence [17]. Finally, a third risk is that our design does not provide a way for us to measure definitively whether an identified orientation (rhetorical or not) is a result of our programme, the natural outcome of other experiences, or the character of the participants.

In our study, we categorized the interviews according to four possible categories:

1. The participant uses rhetorical terminology and shows evidence of having a rhetorical orientation

2. The participant shows evidence of having a rhetorical orientation but does not use rhetorical terminology

3 . The participant uses rhetorical terminology, but does not appear to have a rhetorical orientation

4. The participant neither uses rhetorical terminology nor appears to have a rhetorical orientation [18].

\section{DATA ANALYSIS}

Students returning to the classroom after completing an eight-, twelve-, or sixteen-month Engineering Internship placement were invited to volunteer to be interviewed about their experience while on internship. Four were chosen, two of whom were registered in the communication programme and two who were not. This paper reports on our first two analyses. The interviewer was a graduate of the college, working as a staff member in the college's student service center. Using a semistructured interview format, the interviewer prompted each participant to talk about their internship. The questions did not ask about specific communication issues but rather prompted for story telling about varied professional experiences such as interaction with clients and vendors, feedback from supervisors, mentorship and training opportunities, as well as typical daily duties. The interviewer did not use rhetorical terms when asking questions; however, if the participant introduced rhetorical terminology, the interviewer was able to follow-up using the same terminology.

Each interview was transcribed and subjected to multiple close readings by the authors of this study, two of whom teach rhetoric in the SoPD and the other an engineer who graduated from the college and who had completed a Certificate in Professional Communication in the SoPD. We followed Sonja Foss's (2004) description of the cluster 
method of rhetorical criticism: first we identified key terms in the transcript. Key terms are those that appear to have particular significance for the speaker and are identified by either the frequency or intensity of their use. Often these key terms serve to name a positive or a negative concept, as identified in the context, and are called god or devil terms. The second step involves charting the words that cluster around each key term. Cluster terms are connected to the key term by proximity or logical connection. The third step involves looking for patterns in the clusters that suggest a worldview revealed by language use. Sometimes identified terms can be seen to form oppositions that suggest values that the speaker holds [8]. Once the orientation of the speaker was identified, then language of the clusters was again analyzed, this time looking at terministic screens, to determine not only what the participant selects as worthy of comment but also what the language choice deflects from notice and comment.

\subsection{Interview 1}

Participant 1 described her experience working at a mine site, both above and below ground. Her description of her daily activities and recurring duties included frequent references to interactions with her co-workers and how those interactions helped her learn to do her job.

The first key term we identified in the transcript of her interview was template (see Table 1). This term was selected on the basis of intensity. In a reflection about learning to give presentations at meetings, the participant describes how she made up a template for her supervisor to fill out after every presentation she gave. The template is positioned as a response to the desire to improve and so can be classified as a god term. The participant describes how her supervisor sometimes took up to a week to fill out the form but always found something to say. What is striking about this story is that, in attempting to prompt for feedback on a communication event, the participant chose a medium that de-emphasizes immediate and individualized feedback in favour of a template that enforces a distance between the evaluator and receiver while compelling a standardization of the feedback.

Table 1: Participant One - key term one.

\begin{tabular}{|l|l|}
\hline \multicolumn{2}{|c|}{ Key Term: TEMPLATE } \\
\hline Tool Box Talk & little package \\
& little blurb \\
& our supervisor would lead \\
& those \\
& supervisors would get their \\
& team together/So that was \\
& really neat because that \\
& was something that was \\
\hline
\end{tabular}

\begin{tabular}{|c|c|}
\hline & $\begin{array}{l}\text { really pertinent with safety } \\
\text { short and sweet } \\
\text { didn't ramble like a crazy } \\
\text { amount } \\
\text { very well structured }\end{array}$ \\
\hline Weekly Update & $\begin{array}{l}\text { a newspaper kind of thing } \\
\text { every morning to read }\end{array}$ \\
\hline weekly meetings & $\begin{array}{l}\text { me talking about the } \\
\text { PowerPoint } \\
\text { then getting questions } \\
\text { just chat about that for a } \\
\text { while } \\
\text { then do the same thing again } \\
\text { the next week }\end{array}$ \\
\hline go underground & $\begin{array}{l}\text { I got to know the lingo } \\
\text { switch my focus from more } \\
\text { technical to more...slang } \\
\text { that's what you need to have } \\
\text { credibility with people } \\
\text { underground }\end{array}$ \\
\hline $\begin{array}{l}\text { I made a template } \\
\text { for presentation } \\
\text { feedback }\end{array}$ & $\begin{array}{l}\text { Because communication is } \\
\text { something that's really } \\
\text { important to me }\end{array}$ \\
\hline $\begin{array}{l}\text { Resources on } \\
\text { meeting } \\
\text { management }\end{array}$ & $\begin{array}{l}\text { easy to read } \\
\text { just like really simple about } \\
\text { how to effectively have } \\
\text { meetings } \\
\end{array}$ \\
\hline apology & having to say an apology \\
\hline
\end{tabular}

The unexpectedness of this move of an intern to control feedback from a supervisor led us to read the rest of the transcript with the term template in mind. While the term itself does not recur often, close analysis of the participant's descriptions of other communication events shows that her descriptions are often focused on the genreidentifying and practical aspects of the medium rather than on the interaction that took place. The participant is, in fact, often describing genre when discussing communication events. For example, when describing an online tool used by the company to promote a safety mindset, Tool Box Talk, the participant describes the writing style as "short and sweet" and "very well structured." This tool was used daily in morning team meetings; the suggestion is that the design of the tool facilitated short but important daily team meetings to reinforce the importance of safety. In other words, Tool Box Talk is presented as a successful generic answer to a company-wide concern with safety. Descriptions of other interactions tend to emphasize the repeated and repeatable aspects of the interactions that can be learned and enacted to ensure that the participant showed herself as recognizing conventional expectations and therefore establishing her credibility.

Another incident discussed by the participant furthers the impression that a template (or genre-based message) is valued as a trusted guide to solve communication issues. 
The participant describes a time when she incorrectly filled out a form and submitted it without having it checked by a supervisor. When faced with a challenge to her actions, she responds by deciding to "say an apology." The difference between apologizing, which suggests a particular motivation on the speaker's part, and saying an apology, which suggests relying on the genre to carry and express the motivation, is significant. Carolyn Miller (1984) suggests that genre is often seen only as a response to a recurrent situation; when a recognized series of constraints exists, a predetermined genre of message is created to answer the situation. The analysis of the terms that cluster around the key term template in Participant 1's interview suggest that the participant holds this view of the place and role of genre (or template). However, Miller goes on to suggest that genre should "represent typified rhetorical action" [13]. A genre is a socially-sanctioned response to a social need and is, therefore, persuasive about the relational aspects of the situation.

Analysis of the first key term suggests that Participant 1 relies on templates or predetermined generic responses to communication situations rather than focusing on the relational needs of a situation. The second key term that we identified is resource, and analysis of the terms that cluster around this key term supports this characterization of the participant's orientation (see Table 2). Given that the participant was working in the mining sector where the term resource has a specific, economic force, it is expected that the term is a god term for the participant. Surprisingly then, when used in reference to interactions with people, the key term resource does not seem to expand to include positive relational interactions but remains restricted to this economic definition. For example, in at least two stories, people are presented as being resources that can be "given," "used" and "found." Connections with people are presented as instruments to accomplish tasks, and if the instrument is not the right tool, then it is abandoned in favour of a more efficient one. This is, of course, a valid description of how a professional network works. However, in a work place, one expects to see evidence that one's co-workers and clients are more than simply means to accomplish a task. A resource is not a partner with whom to strive toward a common goal.

Table 2: Participant One - key term two.

\begin{tabular}{|l|l|}
\hline \multicolumn{2}{|c|}{ Key Term: RESOURCE } \\
\hline my boss & $\begin{array}{l}\text { ask my boss like five } \\
\text { questions at a time } \\
\text { book a time } \\
\text { the amount of resources he } \\
\text { was able to give me } \\
\text { resources with getting me } \\
\text { connected with other people }\end{array}$ \\
\hline $\begin{array}{l}\text { list of four or five } \\
\text { companies }\end{array}$ & $\begin{array}{l}\text { no contacts within the } \\
\text { companies } \\
\text { no 'how do I go about talking }\end{array}$ \\
\hline
\end{tabular}

\begin{tabular}{|c|c|}
\hline & $\begin{array}{c}\text { to these people' } \\
\text { I was able to find my own } \\
\text { resources } \\
\text { if they were helpful I would } \\
\text { use them again }\end{array}$ \\
\hline $\begin{array}{c}\text { I had my own little } \\
\text { network of people } \\
\text { in my building }\end{array}$ & $\begin{array}{c}\text { those were kind of my } \\
\text { immediate resources } \\
\text { they would give me some } \\
\text { more people }\end{array}$ \\
\hline
\end{tabular}

The interview process with Participant 1 asked her to reflect the reality of her experiences while on internship. In telling her stories, Participant 1 selected which events to highlight and what terminology to use when describing those events. Analyzing her choices through identifying key terms shows what is important to the speaker; Participant 1 values having tools at her disposal, be they communication templates or sources of knowledge and skills in identified people, that she can depend on to serve a purpose and accomplish a goal. However, Burke tells us that selected terminology also deflects parts of reality while selecting other parts [5]. Participant 1's emphasis on communication and interaction as being instrumental deflects the relational aspects of communication. While she values the use of Tool Box Talk to quickly remind teams of the need for safety, nowhere does she recognize that, in bringing teams together to discuss a safety mentality, the regular morning Tool Box Talks might be increasing safety through solidifying a stronger sense of team, of interdependence, of mutual concern. Participant 1 does not show a significant orientation to a rhetorical interpretation of the world.

\subsection{Interview 2}

Participant 2 discussed his experience working in a large urban office of a resources company that employed many engineers. His description of his daily activities and recurring duties included frequent references to relationships with his co-workers and what he learned about being a professional from those interactions.

The first key term we identified in the transcript of Participant 2's interview was genius (see Table 3). This term was selected on the basis of intensity. When asked about what kind of feedback and mentorship he received from his supervisor, the participant responded but then segued into a story about "one of the most interesting things" that he found at his internship; it was the story of another employer whom he described as a genius. The length of this story and the fact that it was returned to later in the interview suggests that the story has significant import. When the words that cluster around the key term genius are analyzed, it seems that, while initially the key term might be considered a god term, the balance of the clustered words suggest an ultimate judgement from the

CEEA18; Paper 43

University of British Columbia; June 3-6, 2018 
speaker that the term is, at best, ambiguous and perhaps even a devil term.

Table 3: Participant Two - key term one

\begin{tabular}{|l|l|}
\hline \multicolumn{2}{|c|}{ Key Term: GENIUS } \\
\hline $\begin{array}{l}\text { brightest guy in the } \\
\text { company }\end{array}$ & $\begin{array}{l}\text { extremely talented } \\
\text { knew all the theories, all } \\
\text { the equations, could } \\
\text { derive them } \\
\text { his own little tricks and tips } \\
\text { with spreadsheets } \\
\text { really, really smart } \\
\text { in a lot of cases he was } \\
\text { right } \\
\text { we're idiots }\end{array}$ \\
\hline extremely technical & $\begin{array}{l}\text { very black and white } \\
\text { do it the right way or the } \\
\text { wrong way } \\
\text { everything was a technical } \\
\text { problem } \\
\text { there was no convincing } \\
\text { him }\end{array}$ \\
\hline $\begin{array}{l}\text { rubbed a lot of people the } \\
\text { wrong way } \\
\text { communication } \\
\text { skills }\end{array}$ & $\begin{array}{l}\text { to get any traction } \\
\text { he wanted to push forward } \\
\text { he was aware that he was } \\
\text { brash } \\
\text { he was demoted for that } \\
\text { very reason }\end{array}$ \\
\hline people who were \\
successful
\end{tabular}

The story of the genius involved an employee who had been with the company for about ten years. He had once held a vice-president position in the company but had been demoted to manager because of his poor communication skills. The participant's description of the genius sounds much like the accepted stereotype of an engineer: he was "the brightest guy in the company," "extremely talented," "really, really smart," and he "knew all the theories, all the equations, could derive them." This is the positive connotation of genius. A second cluster around the key term concerns the technical orientation of the genius. He is described as "extremely technical," again a usually positive term associated with engineers. However, this cluster has a preponderance of negative terms that suggest, for Participant 2, the "extreme" in the genius' technical ability is a liability. The genius sees every problem as a technical problem and the issues as being "very black and white."
Although he was often right when advocating for a particular technical solution, he let his colleagues know he thought they were "idiots" and so "rubbed a lot of people the wrong way." Being extremely technical seems to involve being unconcerned with the relational aspects of communication. In fact, the third cluster of terms associated with the key term genius seems to suggest that not only does the genius not possess communication skills, but that he is aware of this lack and unconcerned about it. However, because he brashly tried to "push" his ideas, he could not get "any traction" for his point of view. The fourth cluster of terms around the key term genius contrasts the genius' dismissal of the importance of communication skills with those whom the participant witnessed being successful within the company. These people were "not only really smart"; they recognized that "there's always going to be more than one option." Since the technical realities are not different for the genius and these successful people, the further possibilities (that complicate a black and white approach) must rise from the successful people's willingness to consider solutions that colleagues are advocating for but that the genius would dismiss as the ideas of idiots. This final cluster opens up the possibility that genius is a devil term when it leads to the refusal to debate and persuade colleagues. Communication then becomes one of the arbiters, along with technical realities, of what a best solution might be: the best solution is the one that smart people can assess and agree upon.

A second, shorter story in Participant 2's interview adds a further dimension to this depiction of the ability to communicate as a requirement for success. The genius did not maintain corporate success because he did not value communication as a tool to develop consensus. Participant 2 recognized another group of people whose poor communication skills held them back from moving up the corporate ladder (See Table 4). These are the engineers who have English as another language and whose English language skills do not allow them to express themselves adequately or whose pronunciation means that their meaning is not fully conveyed. While Participant 2 seemed to be fascinated by the prospect of the genius' self-limiting behavior, he shows more compassion for these colleagues whom he sees as being "disadvantaged" by "coming from somewhere else." Participant 2 described these engineers as "really, really gifted" who after twenty years at the company were still "just engineers" who had "no opportunity to manage people." The clusters around the key term genius suggest that communication is necessary to reach consensus and to maintain respect and common purpose among colleagues. The clusters around the key term English as other language suggest that communication skills are necessary to manage people, which may go beyond consensus forming. In any case, a cluster around this key term suggests that Participant 2 was willing to put in extra work to learn to understand these 
colleagues and to ensure communication happened, even if it was only on technical issues because the sphere of influence of these engineers was limited.

Table 4: Participant Two - key term two

\begin{tabular}{|c|c|}
\hline \multicolumn{2}{|c|}{ Key Term: EOL } \\
\hline $\begin{array}{l}\text { English wasn't } \\
\text { their first } \\
\text { language }\end{array}$ & $\begin{array}{l}\text { didn't speak English great } \\
\text { they were very difficult to } \\
\text { understand } \\
\text { coming from somewhere else } \\
\text { has disadvantaged them }\end{array}$ \\
\hline $\begin{array}{l}\text { I don't know the } \\
\text { right way to } \\
\text { approach }\end{array}$ & $\begin{array}{l}\text { the more time you spend with } \\
\text { somebody, the better you can } \\
\text { understand } \\
\text { I clarified exactly what they } \\
\text { said } \\
\text { I would repeat back to then } \\
\text { what I had heard }\end{array}$ \\
\hline $\begin{array}{l}\text { really, really } \\
\text { gifted }\end{array}$ & really smart people \\
\hline just engineers & $\begin{array}{l}\text { no opportunity to manage } \\
\text { people }\end{array}$ \\
\hline
\end{tabular}

The stories that Participant 2 selected to reflect the reality of his experiences while on internship revealed a concern with communication skills as an essential companion to technical expertise. The key terms identified in the transcript of this interview show a focus on people. The terms that cluster around those key terms reveal an awareness of the importance of technical expertise (being very smart) and of the equal need for communication skills to create consensus and to manage others. If we look at what this terminology deflects, we can see that Participant 2 's terministic screen is more translucent than opaque. The participant uses a broader scope of terminology that describes communication as being a way to understand technical issues and to persuade others about those technical issues, which opens him to seeing more of the relational aspects of communication. While he values the use of language to understand technical issues, he is equally or more concerned with the need to use language to "convince people that this is the way things should be done." Participant 2 shows strong signs of having a rhetorical orientation in his interactions with others and a worldview that privileges relation building in communication.

\section{CONCLUSION}

This study assessed the terminology that engineering students returning from internship used to describe their experiences to determine whether the students show signs of having a rhetorical orientation. The two interviews considered in this paper present evidence of orientations toward the world.
Only after the analysis of the transcripts was complete and judgements about whether a rhetorical orientation was evident in the participant's terminology did we access information about the participants. Participant 1 is a female who had only taken the required introductory communication course when she returned from internship. Participant 2 is a male who had completed four of six required senior communication courses toward completing a Professional Communication Option.

Participant 1 did not use explicit rhetorical terminology in her descriptions of her experiences, nor did she reveal an orientation or worldview that sees communication as an instrument of persuasion that builds relation even as it transmits information. Rather, Participant 1's choice of terminology tends to deflect recognition of the relational aspects of communication. This participant, who had taken only the required foundational communication course at the time of the interview, had neither a rhetorical orientation nor used rhetorical language.

Participant 2 did not use explicit rhetorical terminology in his descriptions of his experiences; however, he did reveal an orientation that recognizes that communication almost always has a persuasive element that functions not only to condition the audience's acceptance of information, but also to build, maintain, or harm relation. Participant 2's choice of terminology opens up the possibility of perceiving both the instrumental and relational aspects of communication. This participant, who had taken four of the six courses needed to complete an Option in Profession Communication at the time of the interview, had a rhetorical orientation despite not using rhetorical language.

Although this is preliminary information, we can conclude that the participant who had more experience in our communication classrooms and as part of our community of practice showed a marked tendency to interpret his experiences from a rhetorical viewpoint, a tendency that was not perceivable in the participant with minimal experience in our programme. While our results are not able to provide us with conclusive evidence of an identity of practice, the orientation that our analysis of the interviews reveals strongly hints at such an identity. Neither can we conclude that Participant 2's orientation is a result of participating in our programme. However, if the participant entered the College of Engineering with such an orientation, we can suggest that the communication programme encourages retention of a worldview that values good communication skills in a college where being a poor communicator is accepted as a natural part of being an engineer. Ideally, we would like to repeat these interviews with the same participants in five or ten years, in order to determine whether our programme has lasting effects on the orientation, and, possibly, the identity, of the participants. 


\section{Acknowledgements}

The authors would like to thank the Gwenna Moss Centre for Teaching and Learning for providing funding for the Graham School of Professional Development SoTL Cluster. In addition, the authors thank Liz Kuley for conducting the interviews and all the engineering students who agreed to discuss their internship experiences.

\section{References}

[1] David Blakesley, The Elements of Dramatism, New York: Longman, 2002, 212 pp. \{ISBN: 0-205-33712-0\}

[2] Doug Brent, "Transfer transformation, and rhetorical knowledge: insights from transfer theory," Journal of Business and Technical Communication, vol. 25, no. 4, pp. 396-420, 2011.

[3] Kenneth Burke, Attitudes toward History, $3^{\text {rd }}$ ed., Los Angeles: U of California P, 1984, 434 pp. $\{0-520-04148-8\}$

[4] Kenneth Burke, A Rhetoric of Motives, Los Angeles: U of California P, 1969, 333 pp. \{ISBN 13 978-0-520-01546-3\}

[5] Kenneth Burke, "Language as Action: Terministic Screens," On Symbols and Society, ed. Joseph R. Gusfield, Chicago: U of Chicago P, 1989, pp. 114-125. \{ISBN: 0-226-08078-1\}

[6] John W. Creswell, Qualitative Inquiry and Research Design: Choosing among Five Approaches, $2^{\text {nd }}$ ed., Thousand Oaks, CA: Sage Publications, 2007, 369 pp. \{ISBN: 978-1-4129-1606-6\}

[7] George L. Dillon, Rhetoric as Social Imagination: Explorations in the Interpersonal Functions of Language, Bloomington, IN: Indiana UP, 1986, 186 pp. \{978-02-533-50115\}

[8] Sonja K. Foss, Rhetorical Criticism: Exploration and Practice, $3^{\text {rd }}$ ed., Long Grove, IL: Waveland P, 2004, 459 pp. \{ISBN: 978-1-57766318-8\}

[9] James Paul Gee, An Introduction to Discourse Analysis: Theory and Method, $3^{\text {rd }}$ ed., New York: Routledge, 2011, 218 pp. $\{978-415-58569-9\}$

[10] Erving Goffman, “On Face Work," Interaction Ritual, Garden City, NY: Anchor Books, 1967, pp. 5-23. \{ISBN: 97803-947-0631-3\}

[11] Kenneth Kong, Professional Discourse, Cambridge: Cambridge UP, 2014, 282 pp. \{ISBN: 978-1-107-02526-4\}

[12] Jennifer MacLennan, Effective Communication for the Technical Professions, $2^{\text {nd }}$ ed., Don Mills, ON: Oxford UP, 2009, 399 pp. \{ISBN: 978-0-19-542547-5\}

[13] Carolyn Miller, "Genre as social action," The Quarterly Journal of Speech, vol. 70, no. 2, pp 151-167, 1984.

[14] Rebecca Nowacek, Agents of Integration: Understanding Transfer as a Rhetorical Act, Carbondale: Southern Illinois UP,
2011, 167 pp. \{ISBN: 978-0-809-33048-5\}

[15] Corey Owen and Debora Rolfes, "Communication Class Size and Professional Identity," in Proc. ASEE American Society for Engineering Education Conf., (Seattle, WA; 14-17 June 2015), 11 pp., 2015.

[16] Corey Owen and Debora Rolfes, "Situated Professional Communication: A Rhetorical Approach," in Proc. CEEA Canadian Engineering Education Society Conf., (Canmore, AB; 8-11 June 2014), 3 pp., 2014.

[17] Donald E. Polkinghorne, "Validity Issues in Narrative Research," Qualitative Inquiry, vol. 13, no. 4, pp. 471-486, 2007.

[18] Debora Rolfes and Corey Owen, Some Epistemological Groundwork for a Qualitative Analysis of a Communication Community of Practice," in Proc. CEEA Canadian Engineering Education Society Conf., (Halifax, NS; 19-22 June 2016), 6 pp., 2016.

[19] Katie R. Sullivan and April A. Kedrowicz, "Gendered Tensions: Engineering Student's [sic] Resistance to Communication Instruction," Equality, Diversity, and Inclusion: An International Journal, vol. 31, no. 7, pp. 596-611, 2012.

[20] Etienne Wenger, Communities of Practice: Learning, Meaning, and Identity, Cambridge: Cambridge UP, 1998, 318 pp \{ISBN: 978-0-521-66363-2\} 